\title{
Impaired Axonal Regeneration by Isolectin B4-Binding Dorsal Root Ganglion Neurons In Vitro
}

\author{
Pascal G. Leclere, ${ }^{1}$ Emma Norman, ${ }^{1}$ Filitsa Groutsi, ${ }^{2}$ Robert Coffin, ${ }^{2}$ Ulrike Mayer, ${ }^{3}$ John Pizzey, ${ }^{1}$ and David Tonge ${ }^{1}$ \\ ${ }^{1}$ The Wolfson Centre for Age Related Diseases, School of Biomedical and Health Sciences, King's College London, London SE1 1UL, United Kingdom, \\ ${ }^{2}$ Department of Immunology and Molecular Pathology, University College London, London W1T 4JF, United Kingdom, and ${ }^{3}$ Biomedical Research Centre, \\ School of Biological Sciences, University of East Anglia, Norwich NR14 7TJ, United Kingdom
}

The subpopulation of dorsal root ganglion (DRG) neurons recognized by Griffonia simplicifolia isolectin B4 (IB4) differ from other neurons by expressing receptors for glial cell line-derived neurotrophic factor (GDNF) rather than neurotrophins. Additionally, IB4labeled neurons do not express the laminin receptor, $\alpha 7$-integrin (Gardiner et al., 2005), necessary for optimal axonal regeneration in the peripheral nervous system. In cultures of dissociated DRG neurons of adult mice on laminin, robust spontaneous neurite outgrowth from IB4-negative neurons occurs and is strongly enhanced by previous axotomy. In contrast, IB4-labeled neurons show little neurite outgrowth and do not express GAP 43, even after axotomy or culture with GDNF. Moreover, growth of their axons through collagen gels is impaired compared with other DRG neurons. To determine whether the sparse neurite outgrowth of IB4-labeled neurons is attributable to lack of integrin expression, DRG cultures were infected with a herpes simplex 1 vector encoding $\alpha 7$-integrin, but its forced expression failed to promote neurite outgrowth in either IB4-labeled or other DRG neurons or in cultured adult retinal ganglion cells. Forced coexpression of both $\alpha 7$-integrin and GAP 43 also failed to promote neurite outgrowth in IB4-labeled neurons. In addition, cultured sciatic nerve segments were found to release much lower levels of GDNF, demonstrated by ELISA, than nerve growth factor. These findings together with their impaired intrinsic axonal regeneration capacity may contribute to the known vulnerability of the IB4-labeled population of DRG neurons to peripheral nerve injury.

Key words: DRG; IB4; $\alpha 7$-integrin; GAP 43; SPRR1A; axonal regeneration

\section{Introduction}

Mammalian dorsal root ganglia (DRGs) contain separate populations of neurons expressing receptors for different neurotrophic factors, essential for neuronal survival during development (Baudet et al., 2000; Huang and Reichardt, 2001). Large- and intermediate-sized neurons generally express trkC or trkB, which act as receptors for neurotrophin-3 (NT-3) or brain-derived neurotrophic factor (BDNF) and neurotrophin-4 (NT-4), respectively. Many small-diameter neurons express trkA, the receptor for nerve growth factor (NGF), whereas others, recognized by isolectin B4 (IB4), express receptors for glial-derived neurotrophic factor (GDNF), neurturin, or artemin (Baloh et al., 2000; Bennett et al., 2000). In adult animals, DRG neurons do not depend on neurotrophic factors for survival (Lindsay, 1988), but aspects of their phenotype, such as expression of receptors for bradykinin, may be influenced by neurotrophic factors (Lee et al., 2002; Vellani et al., 2004).

In addition to promoting neuronal survival, neurotrophins strongly stimulate axonal growth of embryonic DRG neurons

\footnotetext{
Received Aug. 21, 2006; revised Dec. 14, 2006; accepted Dec. 16, 2006.

This work was supported by the Biotechnology and Biological Sciences Research Council and the Wellcome Trust. We thank Prof. P. Caroni for the cDNA encoding mouse GAP 43.

Correspondence should be addressed to Dr. David Tonge, The Wolfson Centre for Age Related Diseases, School of Biomedical and Health Sciences, King's College London, Guy's Campus, London SE1 1UL, UK. E-mail: david.tonge@kcl.ac.uk.

DOI:10.1523/JNEUROSCI.5089-06.2007

Copyright $\odot 2007$ Society for Neuroscience $\quad$ 0270-6474/07/271190-10\$15.00/0
}

(Huang and Reichardt, 2001). NGF, NT-3, and GDNF also promote axonal regeneration of adult neurons (Mohiuddin et al., 1995; Edström et al., 1996; Naveilhan et al., 1997; Leclere et al., 1998; Gavazzi et al., 1999; Ramer et al., 2000; Fine et al., 2002). BDNF does not stimulate growth of DRG axons in adult rodents (Malgrange et al., 1994; Edström et al., 1996; Kimpinski et al., 1997; Gavazzi et al., 1999), but BDNF and NT-4 both stimulate axonal growth from nodose ganglia (Wiklund and Ekström, 2000). After peripheral nerve (PN) lesions, synthesis of NGF, BDNF, NT-4, and GDNF increases (Meyer et al., 1992; Funakoshi et al., 1993; Trupp et al., 1995; Naveilhan et al., 1997; Bar et al., 1998; Hoke et al., 2000, 2002; Dethleffsen et al., 2002). Because NGF and GDNF stimulate axonal growth from DRG neurons in vitro and in vivo (Edström et al., 1996; Naveilhan et al., 1997; Leclere et al., 1998; Gavazzi et al., 1999; Ramer et al., 2000; Fine et al., 2002), their upregulation in lesioned peripheral nerves might be expected to promote axonal regeneration.

During peripheral nerve regeneration, axons grow in association with the basal laminas of endoneurial tubes (for review, see Ide, 1996) containing laminin, which strongly supports axonal growth (for review, see Luckenbill-Edds, 1997). After peripheral nerve lesions, the laminin receptor $\alpha 7 \beta 1$-integrin is upregulated in both sensory and motor neurons (Werner et al., 2000; Ekström et al., 2003; Wallquist et al., 2004; Gardiner et al., 2005), and dissociated DRG neurons show enhanced neurite outgrowth on laminin (Hu-Tsai et al., 1994; Smith and Pate Skene, 1997; Lankford et al., 1998). However, Gardiner et al. (2005) showed that, 

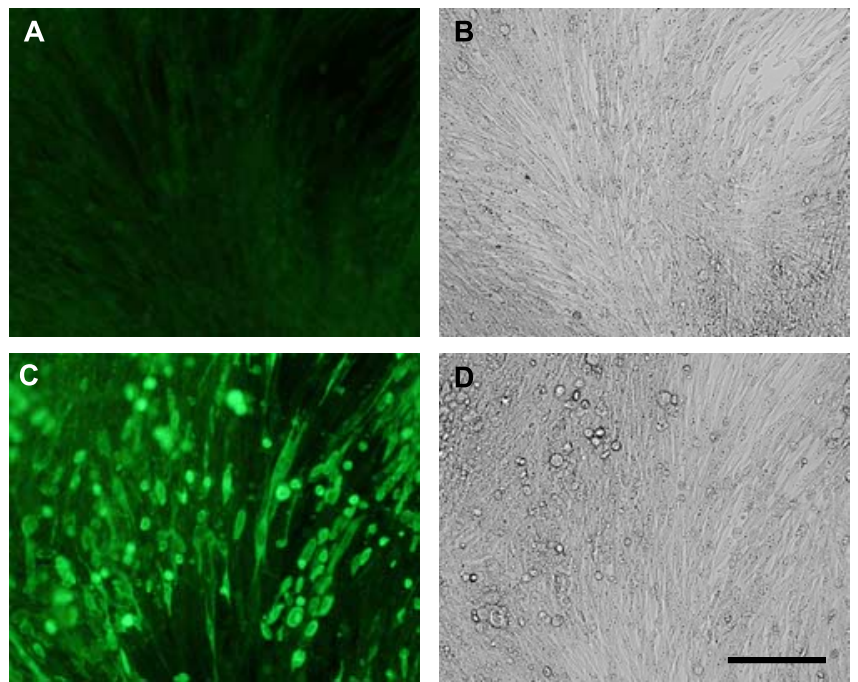

Figure 1. BHK cells infected with HSV-1- $\alpha 7$-integrin. Normal BHK cells viewed under fluorescence $(\boldsymbol{A}, \boldsymbol{C})$ and phase contrast $(\boldsymbol{B}, \boldsymbol{D})$ after labeling with antibody to $\alpha 7$-integrin. In uninfected cells $(\boldsymbol{A})$, low background fluorescence is visible, whereas in cultures infected with HSV$1-\alpha 7$-integrin (C), many cells show strong immunofluorescence. Scale bar, $100 \mu \mathrm{m}$.

after peripheral nerve lesions, $\alpha 7$-integrin expression increased mainly in large- and medium-sized DRG neurons but not in small-diameter nonpeptidergic neurons labeled by IB4, raising the possibility that their axonal regeneration might be impaired.

In the present investigations, we show that neurite outgrowth of IB4-labeled neurons on laminin is inferior to that of IB4negative neurons and that they do not express GAP 43 after peripheral nerve lesions, suggesting that axonal regeneration of IB4-labeled neurons is intrinsically different to that of other DRG neurons.

\section{Materials and Methods}

All reagents were purchased from Sigma (Poole, UK) unless otherwise stated.

Surgery. Eight Wistar rats (70-80 g; Harlan, Bicester, UK) and $\sim 100$ female mice aged 6-12 weeks [BK1 TO strain; Tuck and Son (London, UK) or bred at King's College (London, UK)] were anesthetized as described previously (Flecknell and Mitchell, 1984). The sciatic nerve was exposed and cut in one limb, followed by closure of the skin incision by wound clips. After recovery, the animals were allowed to survive for $3 \mathrm{~d}$ before being killed by anesthetic overdose.

Preparation of herpes simplex 1 vectors encoding green fluorescent protein or $\alpha 7$-integrin. An EcoRI fragment containing the full-length coding sequence of mouse $\alpha 7$-integrin was cut out of PUC/ $\alpha 7 \mathrm{BX} 2$ (Eble et al., 2003) and ligated into pcDNA3.1. After checking its orientation, the insert was removed and subcloned into the green fluorescent protein (GFP) site in the latency-associated transcript (LAT) region of pR19GFP (Lilley et al., 2001), resulting in pR19- $\alpha 7$-integrin. Expression of $\alpha 7$-integrin in COS-7 cells transfected with pR19- $\alpha 7$-integrin using Lipofectamine2000 (Invitrogen, Carlsbad, CA) was confirmed by immunocytochemistry (data not shown).

Herpes simplex 1 (HSV-1) vectors encoding $\alpha 7$-integrin were generated using procedures as described previously (Lilley et al., 2001). Briefly, pR19- $\alpha 7$-integrin was linearized and recombined with the LAT regions of HSV-1-GFP after transfection into baby hamster kidney (BHK) 27/ 12/M:4 cells (Thomas et al., 1999). Recombinant viruses, identified as nonfluorescent plaques, were purified by picking and replating until fluorescence was no longer visible. Wells of normal BHK cells were infected with the purified HSV-1- $\alpha 7$-integrin virus and labeled using anti- $\alpha 7$ integrin, the one yielding the greatest infectivity and strongest labeling (Fig. 1) was expanded in BHK 27/12/M:4 cells, which were then freeze thawed, and cell debris was removed by centrifugation and filtration. The viral titers of HSV-1-GFP (control) and HSV-1- $\alpha 7$-integrin, determined after serial dilution on BHK 27/12/M:4 cells, were $4 \times 10^{8}$ and $10^{7}$ pfu, respectively.

Tissue culture. Cultures were maintained in RPMI 1640 medium containing $100 \mathrm{U}$ of penicillin, $100 \mu \mathrm{g}$ of streptomycin, and $250 \mathrm{ng}$ of amphotericin $\mathrm{B}$ per milliliter and maintained at $37^{\circ} \mathrm{C}$ in an atmosphere of $5 \% \mathrm{CO}_{2}$.

After the mice were killed, L4 and L5 DRGs were removed, trimmed, and incubated in $0.125 \%$ collagenase type III (Worthington, Freehold, $\mathrm{NJ})$ for $3 \mathrm{~h}$ at $37^{\circ} \mathrm{C}$, followed by trituration in RPMI medium containing $10 \%$ horse serum and filtration through a $70 \mu \mathrm{m}$ cell strainer (BD Falcon, Bedford, MA). The dissociated cells were plated into eight-well chamber slides (BD Biosciences, San Diego, CA), coated with poly-L-lysine and 10 $\mu \mathrm{g} / \mathrm{ml}$ laminin-1 (BD Biosciences) in PBS at a density of $\sim 1000$ cells per well. To some wells, $50 \mathrm{ng} / \mathrm{ml}$ recombinant rat GDNF (CN Biosciences, Nottingham, UK) was added. In other experiments, DRG cells were infected, immediately after plating, with disabled HSV-1 particles encoding GFP or $\alpha 7$-integrin using multiplicities of infection (MOI) of 0.1 and 1.0. Starting from the original viral titer, the volume of viral particle suspension added to the cells was determined by the following formula: vol $(\mathrm{ml})=$ MOI $\times$ number of target cells/well/titer of stock $(\mathrm{pfu} / \mathrm{ml})$. Cultures were usually incubated for $1-3 \mathrm{~d}$ followed by fixation for $1 \mathrm{~h}$ with $3.6 \%$ paraformaldehyde in PBS.

Electroporation. As a first experiment (data not shown), we confirmed that, in COS-7 cells transfected with 10:10:1 ratio of cDNAs encoding $\alpha 7$-integrin, GAP 43 , and GFP (respectively), GFP-positive cells generally also expressed $\alpha 7$-integrin and GAP 43 , as expected. Dissociated DRG cells from postnatal day 5 (P5) and P6 mice were then transfected with the same ratio of plasmids using the electroporation technique from Amaxa (Cologne, Germany). Briefly, cells were spun down and resuspended in $100 \mu \mathrm{l}$ of electroporation buffer containing a total of $2.5 \mu \mathrm{g}$ of plasmids comprising pcDNA 3.1 encoding GAP 43 and pR19- $\alpha 7$ integrin, together with pR19-GFP to facilitate detection of transfected cells. After electroporation using an Amaxa Nucleofector apparatus, cells were transferred to eight-well coverslips coated with laminin.

Explant cultures. In some experiments, short lengths of intercostal nerves with attached DRGs (PN-DRGs) were removed and cultured in shallow gels of type 1 collagen (Tonge et al., 1998) in multiwells with 0.5 $\mathrm{ml}$ of RPMI medium. To some cultures, $50 \mathrm{ng} / \mathrm{ml}$ recombinant rat GDNF or human NGF (PeproTech, Rocky Hill, NJ) were added. Conditioned media (CM) was obtained by culturing (in $500 \mu$ l of RPMI medium for $4 \mathrm{~d}$ ) lengths of $\sim 5 \mathrm{~mm}$ of normal rat and mouse sciatic nerves or the distal stumps of nerves, which had been cut in situ $4 \mathrm{~d}$ previously. To some batches of CM, $500 \mathrm{ng} / \mathrm{ml}$ of an antibody to NGF [monoclonal antibody (mAb) 27/21; Boehringer Mannheim, Mannheim, Germany] was added, which in preliminary experiments, neutralized effects of 100 $\mathrm{ng} / \mathrm{ml}$ 2.5S NGF on axonal outgrowth from mouse PN-DRGs in collagen gels (our unpublished observations). After $3 \mathrm{~d}$ culture, preparations were fixed with formaldehyde in PBS for $\sim 1 \mathrm{~h}$.

Immunocytology and stereography. After fixation and washing with PBS, dissociated DRG neurons and PN-DRG preparations in collagen gels were blocked with $3 \%(\mathrm{w} / \mathrm{v})$ bovine serum albumin (BSA) and $0.1 \%$ $(\mathrm{w} / \mathrm{v})$ Triton X-100 in PBS for $1 \mathrm{~h}$. Alternatively, some live DRG neurons were labeled directly using $10 \mu \mathrm{g} / \mathrm{ml}$ fluorescein-labeled IB4 (Vector Laboratories, Burlingame, CA) in RPMI medium for $20 \mathrm{~min}$ at room temperature or sequentially with biotin-conjugated IB4 (Vector Laboratories) and tetramethylrhodamine isothiocyanate (TRITC)-conjugated avidin, followed by fixation and blocking with BSA and Triton X-100.

Dissociated DRG neurons were incubated at room temperature for $1 \mathrm{~h}$ using primary antibodies at the concentrations shown in Table 1, followed by washing with PBS and labeling with appropriate Alexa 488- or 568 -conjugated secondary antibodies (1:200 dilution) raised in donkey or goat (Invitrogen) for $30 \mathrm{~min}$. After washing in PBS, the cultures were mounted in Vectashield containing 4',6'-diamidino-2-phenylindole (DAPI) (Vector Laboratories), coverslipped, and viewed using either Eclipse TE200 (Nikon, Tokyo, Japan) or Olympus Optical (Tokyo, Japan) AX70 fluorescence microscopes, and images were captured using Nikon DXM1200F or Zeiss (Oberkochen, Germany) AxioCam HRm digital cameras, respectively. Neurite outgrowth was quantified from the digital images by measuring the longest neurite of 15-20 neurons, labeled 
by IB4, mAb RT97, or antibodies to $\beta$ IIItubulin per experiment, using a personal computer version of NIH Image (Scion, Frederick, $\mathrm{MD)}$. Relative expression levels of $\beta$ III tubulin and protein gene product PGP 9.5 were assessed by comparing the averaged immunofluorescence intensity of labeled axons against background at three points using Scion Image. For each antibody, images were captured using the same exposure time.

To quantify axonal outgrowth from PNDRGs in collagen gels, preparations were labeled using pan-axonal antibodies to PGP 9.5 or $\beta$ III-tubulin and visualized using peroxidase-conjugated avidin as described previously (Tonge et al., 1998). The stained preparations were mounted in glycergel (DakoCytomation, High Wycombe, UK) and viewed under dark-ground illumination using a microscope with an image projection tube. Camera lucida drawings were made of the longest axons growing from the cut ends of the peripheral nerves (usually 10-20 per preparation), and their lengths were determined using Scion Image. Some PN-DRG preparations in collagen gels were incubated with biotinylated IB4 overnight and washed with PBS next day, followed by addition of cyanine 3 (Cy3)-conjugated avidin (Jackson ImmunoResearch, West Grove, PA), diluted 1:200 overnight. Finally, preparations were washed with PBS, mounted in Citifluor (Agar Scientific, Stansted, UK), and viewed with an Olympus Optical B4 fluorescence microscope.

Determination of NGF and GDNF concentrations by ELISA. The concentrations of NGF and GDNF in CM were determined by ELISA kits, following the protocols of the manufacturer (Promega, Madison, WI). The NGF standard was $98 \%$ pure mouse salivary gland 2.5 S NGF (Promega). Recombinant human GDNF was supplied with the kit as standard, but, because the sequences of human and mouse GDNF are not identical, the sensitivity of the kit in their detection may differ. Because of lack of available recombinant mouse GDNF, GDNF levels in media conditioned by rat lesioned sciatic nerve segments using recombinant rat GDNF (CN Biosciences) as standard were also determined.

Statistical analysis. Results are expressed as means \pm SEM, and $n$ refers to the number of different animals used, unless otherwise stated. The differences between means were evaluated by a Student's $t$ test and were considered significant at $p<0.05$.

\section{Results}

IB4-labeled neurons show impaired neurite outgrowth on laminin

To compare neurite outgrowth of different neuronal classes, lumbar DRGs were removed $3 \mathrm{~d}$ after sciatic nerve section, together with unoperated contralateral DRGs. After dissociation and culture on laminin overnight, cells were fixed and processed for immunocytochemistry. In preliminary experiments, we attempted to differentiate between different classes of DRG neuron in cultures using IB4 and antibodies to calcitonin gene-related peptide (CGRP) and heavy neurofilament (NFH) as used in other studies (Averill et al., 1995; Gardiner et al., 2005). However, we found extensive overlap between $\mathrm{NFH}$ - and CGRP-positive neurons and also some overlap between CGRP-positive and IB4-labeled neurons. In subsequent experiments, we therefore used mAb RT97, which recognizes phosphorylated heavy neurofilaments but does not bind to IB4-labeled neurons (McMahon et al., 1994).

In cultures of cells from control (nonlesioned) DRGs, robust neurite outgrowth from RT97-positive neurons was observed, in the absence of added growth factors (Fig. 2A), but very few IB4labeled neurons extended neurites, and these were significantly $(p<0.02)$ shorter than the RT97-positive neurites (Fig. $2 B$ ) as summarized in Table 2. However, in separate experiments in which GDNF was added to cultures, $52 \pm 10 \%(n=3)$ of IB4-
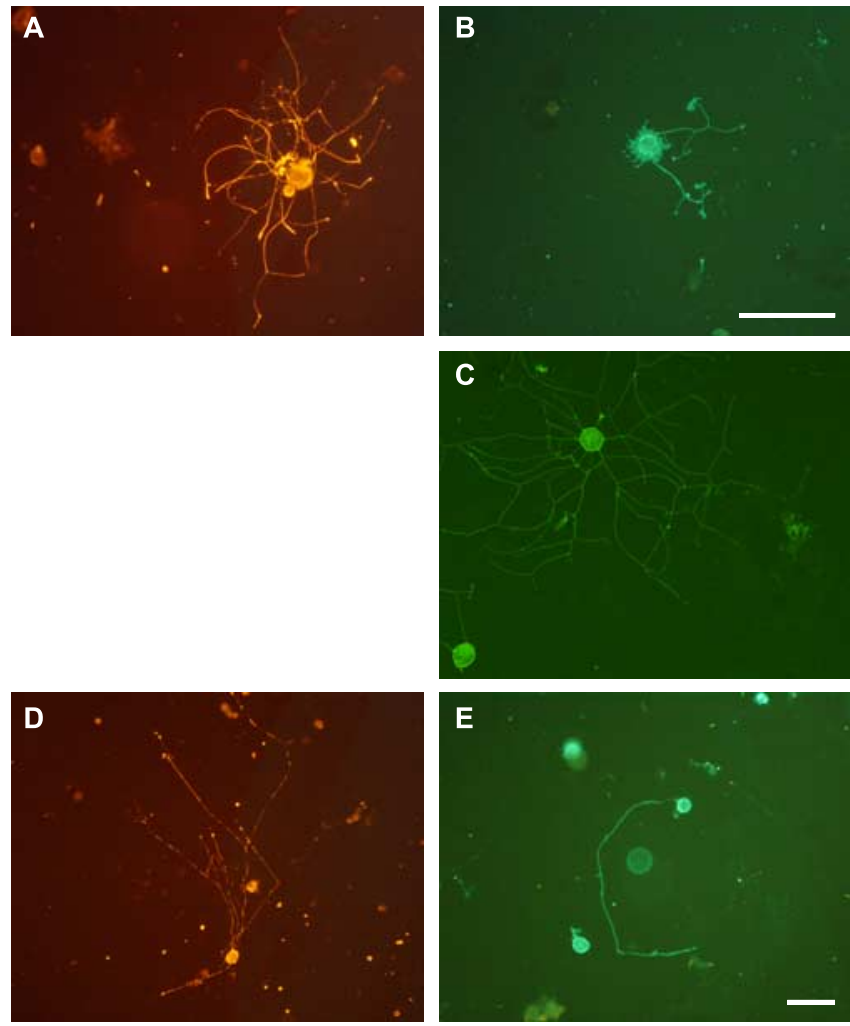

Figure 2. Spontaneous neurite outgrowth from IB4-labeled neurons is shorter than that from RT97-labeled neurons. Dissociated DRG cells cultured on laminin for $1 \mathrm{~d}$, labeled with IB4 $(\boldsymbol{B}, \boldsymbol{C}, \boldsymbol{E})$ or mAb RT97 $(\boldsymbol{A}, \boldsymbol{D})$ showing neurite outgrowth from normal $(\boldsymbol{A}, \boldsymbol{B})$, primed $(\boldsymbol{D}, \boldsymbol{E})$, or GDNF-treated neurons (C). Scale bars, $100 \mu \mathrm{m}$ ( $\boldsymbol{A}$ applies to $\boldsymbol{A}, \boldsymbol{B} ; \boldsymbol{C}$ applies to $\boldsymbol{C}-\boldsymbol{E}$ ).

labeled neurons extended neurites, often with extensive outgrowth (Fig. 2C) as observed by other investigators (Gavazzi et al., 1999; Gardiner et al., 2005). In cultures of cells from DRGs that had been primed by sciatic nerve section $3 \mathrm{~d}$ previously (Fig. $2 D, E)$, the proportions of both RT97-positive and IB4-labeled neurons extending neurites were significantly increased compared with controls ( $p<0.001$ and $p<0.05$, respectively), as were their lengths ( $p<0.05$ and $p<0.001$, respectively). However, the proportion of IB4-labeled neurons with neurites and their lengths were significantly less than for the RT97-positive population ( $p<0.05$ and $p<0.001$, respectively), as summarized in Table 2 .

\section{IB4-labeled neurons do not express GAP 43}

GAP 43 is a well established marker for growing axons during development and regeneration (for review, see Benowitz and 
Table 2. Neurite outgrowth from IB4-labeled neurons is inferior to that from RT97positive neurons

\begin{tabular}{lll}
\hline & Controls & Conditioned \\
\hline IB4 & $127 \pm 34 \mu \mathrm{M}$ & $260 \pm 13 \mu \mathrm{M}$ \\
& $(2.1 \pm 0.1 \%)$ & $(13.7 \pm 4.9 \%)$ \\
RT97 & $260 \pm 8 \mu \mathrm{M}$ & $470 \pm 14 \mu \mathrm{M}$ \\
& $(19.3 \pm 1.4 \%)$ & $(30.3 \pm 3.1 \%)$ \\
\hline
\end{tabular}

Mean lengths of neurites labeled with IB4 or mAb RT97 and proportions of neurons extending neurites (in parentheses) on laminin $(n=3)$.
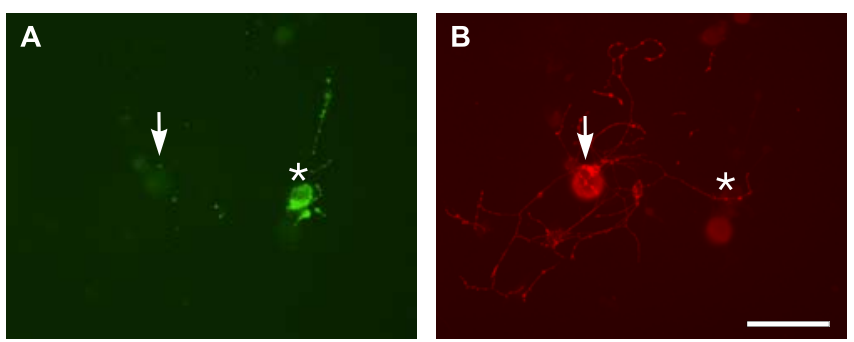

Figure 3. IB4-labeled dissociated DRGs do not express GAP 43. Dissociated cells from normal DRGs cultured on laminin for $1 \mathrm{~d}$ labeled with IB4 (A) or antibody to GAP 43 (B). Neurons labeled by IB4 (asterisk) do not express GAP 43, whereas GAP 43-expressing neurons (arrow) are not labeled by IB4. Scale bar, $100 \mu \mathrm{m}$.

Routenberg, 1997) and, in cultures of dissociated DRG cells, labels most neurons in their entirety (Gavazzi et al., 1999). In view of the relative lack of neurite outgrowth from IB4-labeled neurons on laminin, expression of GAP 43 in this population was therefore investigated by immunocytochemistry. Surprisingly, although most neurons from both control and primed DRGs were strongly labeled by an antibody to GAP 43, those neurons labeled by IB4 ( $\sim 30 \%$ of all plated DRG neurons) were almost invariably (>99\%) GAP 43 negative (Fig. 3). In contrast, expression of the small proline-rich repeat protein 1A (SPRR1A), another marker of regenerating axons (Bonilla et al., 2002), occurred in both IB4-labeled and IB4-negative neurons from primed DRGs (Fig. 4C,D), indicating differences in mechanisms regulating its expression and that of GAP 43. We also investigated expression of $\beta$ III-tubulin in cultured DRG neurons, because this is known to increase during axonal regeneration (Moskowitz and Oblinger, 1995). IB4-labeled neurons were found to express $\beta$ IIItubulin, but labeling of their axons by immunofluorescence was significantly less intense than for DRG neurons not labeled by IB4 ( $52 \pm 30$ vs $74 \pm 26$ arbitrary units respectively; $n=3 ; p<0.05$ ) (Fig. $5 A, B$ ). In contrast, labeling intensities for PGP $9.5 \mathrm{kDa}$ [which recognizes ubiquitin C-terminal hydrolase (Wilson et al., 1988)] were similar in both IB4-labeled and IB4-negative neurons (53 \pm 2 vs $53.6 \pm 15$ arbitrary units, respectively; results from two pooled experiments; $p>0.05$ ) (Fig. $5 C, D$ ). These findings suggest that the expression of proteins associated with axonal growth differs in neurons labeled by IB4 from other populations of DRG neurons.

\section{Integrin expression}

DRG neurons in adult animals express the laminin receptor $\alpha 7 \beta 1$ (Werner et al., 2000; Ekström et al., 2003). However, Gardiner et al. (2005) recently showed that, although the $\alpha 7$-integrin subunit was expressed by CGRP- and NFH-positive neurons, it was not expressed by IB4-labeled neurons. In view of the possibility that lack of $\alpha 7$-integrin expression in the IB4-labeled neurons might explain their poor neurite outgrowth on laminin, we constructed an $\mathrm{HSV}$-1 vector containing cDNA encoding the $\alpha 7 \mathrm{BX} 2$-integrin
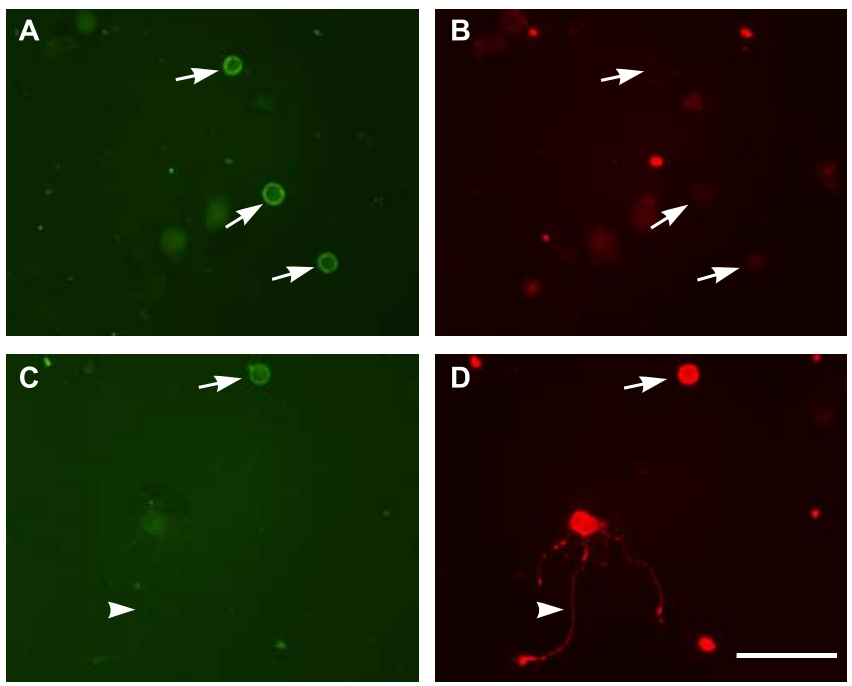

Figure 4. IB4-labeled DRGs express SPRR1A after axotomy in vivo. Dissociated cells from normal $(A, B)$ and conditioned $(C, D)$ DRGs cultured on laminin for 1 d labeled with IBA $(A, C$ or antibody to SPRR1A. Dissociated neurons from normal DRGs do not express SPRR1A ( $\boldsymbol{B})$, but, in cultures from conditioned DRGs, it is expressed by both IB4-labeled (arrow) and IB4-negative (arrowhead) neurons (D). Scale bar, $100 \mu \mathrm{m}$.
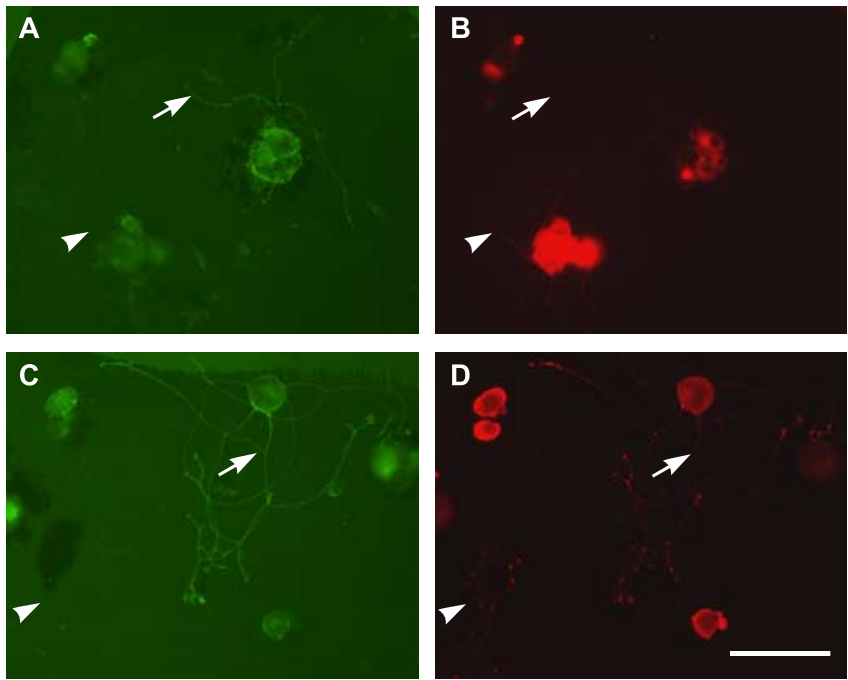

Figure 5. IB4-labeled neurons express lower levels of $\beta$ III-tubulin. Dissociated cells from normal DRGs, cultured for $1 \mathrm{~d}$ on laminin, labeled using IB4 $(A, C)$, and antibodies to $\beta$ III-tubulin (B) or PGP 9.5 (D). In $\boldsymbol{A}$ and $\boldsymbol{B}$, IB4-labeled neurons show fainter $\beta$ III-tubulin immunofluorescence (arrow) than IB4-negative neurons (arrowhead), whereas PGP 9.5 immunofluorescence intensities for IB4-labeled (arrow) and IB4-negative (arrowhead) neurons are similar $(\boldsymbol{C}, \boldsymbol{D})$. Scale bar, $100 \mu \mathrm{m}$.

isoform, normally expressed in DRGs (Ekström et al., 2003). In DRG cell cultures infected by this viral construct, $\sim 60-70 \%$ of cells appeared infected, with strong expression of $\alpha 7$-integrin in $\beta$ III-tubulin-positive neurons within $1 \mathrm{~d}$ (data not shown) and in other cultures persisting for at least $3 \mathrm{~d}$ (Fig. $6 C, D$ ). In initial experiments, neurite outgrowth in cultures infected with the vector encoding $\alpha 7$-integrin appeared to be substantially greater than in cultures infected with the vector encoding GFP. However, GFP intensity in neurites tended to decline distally and especially in small branches that were difficult to see (data not shown), raising the possibility that neurite outgrowth might be underestimated. In later experiments $(n=4)$, cultures were therefore labeled using the polyclonal antibody to GFP, and, under these 

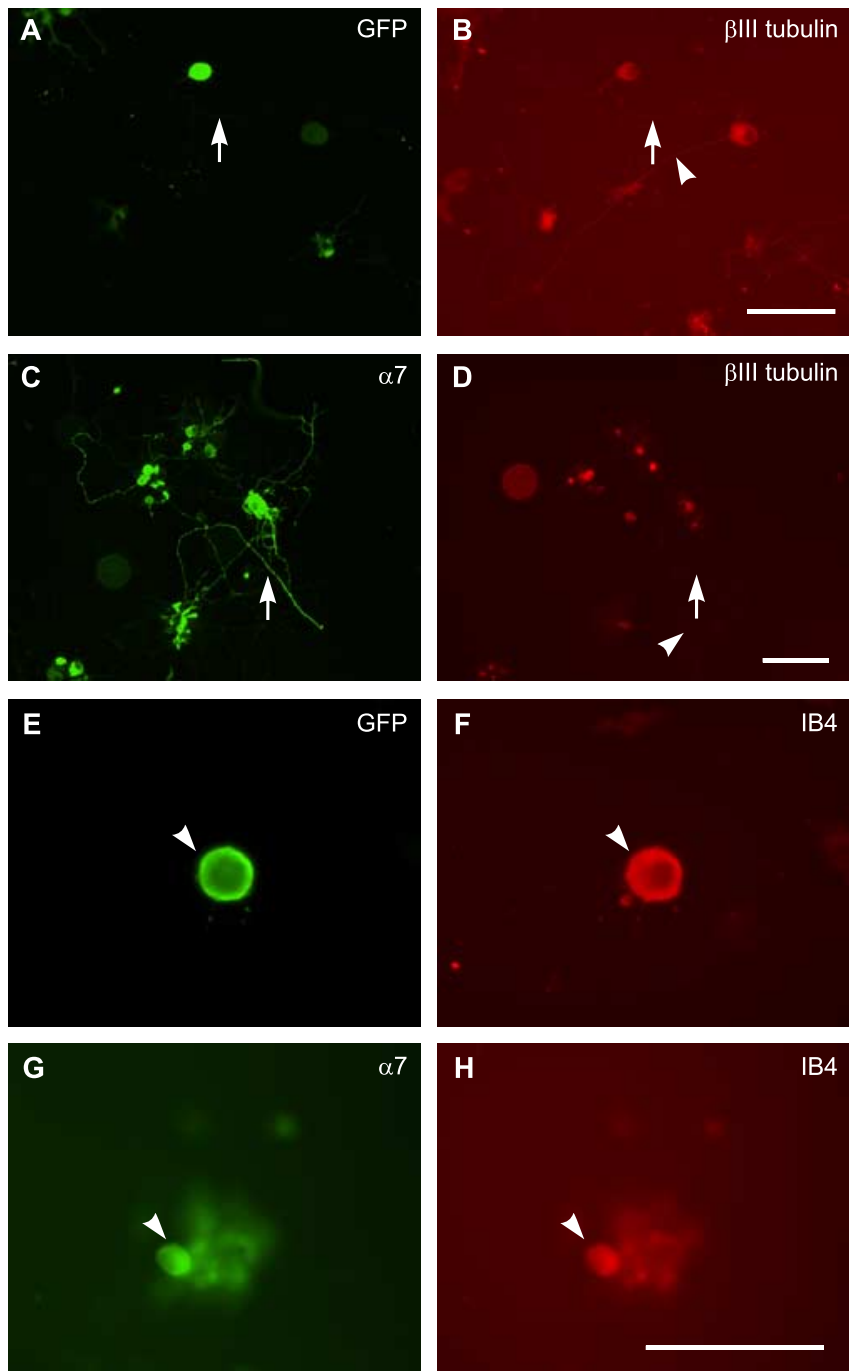

Figure 6. Infection of IB4-labeled DRGs with HSV-1- $\alpha 7$-integrin does not enhance axonal regeneration. Dissociated DRG cells cultured on laminin for $3 \mathrm{~d}$ after infection with the HSV-1$\operatorname{GFP}(\boldsymbol{A}, \boldsymbol{B}, \boldsymbol{E}, \boldsymbol{F})$ or HSV- $1-\alpha 7$-integrin $(\boldsymbol{C}, \boldsymbol{D}, \boldsymbol{G}, \boldsymbol{H})$, labeled green using antibodies to GFP $(\boldsymbol{A}, \boldsymbol{E})$ or $\alpha$-integrin $(\boldsymbol{C}, \boldsymbol{G})$ or red using an antibody to $\beta$ Ill-tubulin $(\boldsymbol{B}, \boldsymbol{D})$ or IB $4(\boldsymbol{F}, \boldsymbol{H})$. Many neurons expressing GFP $(\boldsymbol{A})$ or $\alpha$-integrin $(\boldsymbol{C})$ show extensive neurite outgrowth (arrow), as do noninfected neurons visualized by $\beta$ III-tubulin immunoreactivity (arrowheads). However, neurons labeled by IB4 (arrowhead in $\boldsymbol{F}, \boldsymbol{H}$ ) expressing GFP $(\boldsymbol{E})$ or $\alpha$-integrin $(\boldsymbol{G})$ seldom show neurite outgrowth. Scale bars, $100 \mu \mathrm{m}$.

conditions, after $3 \mathrm{~d}$ in culture, the mean lengths of the longest neurites of neurons labeled for $\beta$ III-tubulin (10-19 per experiment) after infection with either HSV-1-GFP or HSV-1- $\alpha 7$ integrin were very similar ( $400 \pm 56$ and $480 \pm 66 \mu \mathrm{m}$; respectively) (Fig. $6 A-D)$. IB4-labeled DRG neurons $(n=3)$ were also successfully infected with HSV-1- $\alpha 7$-integrin (Fig. $6 G, H$ ) and HSV-1-GFP (Fig. 6E, F), but only a few (7-13 per experiment) extended neurites and the mean lengths of those expressing either GFP or $\alpha 7$-integrin were also very similar ( $239 \pm 60$ and $234 \pm 49$ $\mu \mathrm{m}$, respectively). Numbers and branching of neurites of infected neurons appeared similar in both cases and were therefore not quantified. These results indicate that forced expression of $\alpha 7$-integrin fails to enhance neurite outgrowth of IB4-labeled DRG neurons.

In adult animals, RGCs express $\beta 1$-integrin (Bates and Meyer, 1997 ) but they do not express $\alpha 7$-integrin, and their axons generally fail to regenerate after axotomy (Werner et al., 2000). We
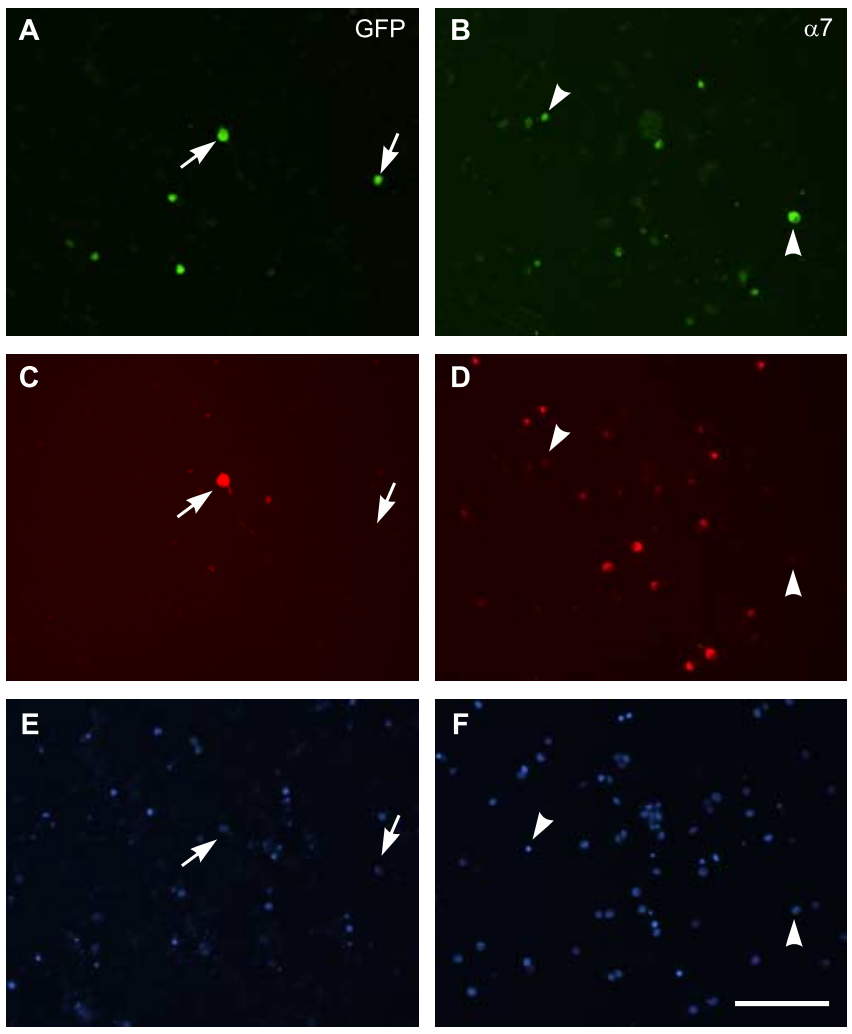

Figure 7. Infection of RGCs with HSV-1- $\alpha$-integrin does not increase axonal regeneration. Dissociated retinal cells cultured on laminin-2 for $3 \mathrm{~d}$ after infection with HSV-1- $\alpha 7$-integrin or HVS-1-GFP, labeled green with antibodies to GFP $(\boldsymbol{A})$ or $\alpha 7$-integrin $(\boldsymbol{B})$ and red using an antibody to $\beta$ III-tubulin to visualize neurons. $\boldsymbol{E}$ and $\boldsymbol{F}$ show the nuclei of all cells labeled with DAPI. Retinal neurons expressing GFP occasionally extend neurites (arrow), but very few of those expressing $\alpha$-integrin (arrowheads) showed neurite outgrowth. Scale bar, $100 \mu \mathrm{m}$.

therefore also infected cultures of dissociated retinal cells on laminin with HSV-1 encoding either GFP or $\alpha 7$-integrin but observed no stimulation of neurite outgrowth (Fig. 7). It is likely that expression of proteins additional to integrins (such as cytoskeletal proteins and/or appropriate signaling molecules) may be required to enable RGCs to extend neurites on laminin.

\section{Forced coexpression of $\alpha 7$-integrin and GAP 43}

Although our results show that forced expression of $\alpha 7$-integrin by itself failed to promote neurite outgrowth, in previous studies (Bomze et al., 2001; Zhang et al., 2005), forced coexpression of GAP 43 with the functionally related protein CAP 23 or the cell adhesion molecule L1 were found to enhance axonal regeneration in vivo. To determine whether forced expression of GAP 43 together with $\alpha 7$-integrin could stimulate neurite outgrowth from IB4-labeled DRG neurons, we initially electroporated cDNAs encoding both genes and GFP into dissociated DRG cells of adult mice, but relatively few GFP-positive neurons were observed compared with results obtained in our previous experiments using cultured adult rat DRG cells (Leclere et al., 2005). In contrast, electroporation of the plasmids into dissociated DRG cells of neonatal (P5-P6) mice appeared more effective. Because we also found that cultures of neonatal DRG cells were similar to those from adult mice in that IB4-labeled neurons were generally GAP 43 negative and that the proportion of IB4-labeled neurons extending neurites $(4.5 \pm 0.9 \%)$ and their mean lengths (95 \pm $11.3 \mu \mathrm{m}$ ) were much lower than the corresponding values for GAP 43-positive neurons $(77.9 \pm 5.1 \%$ and $251.3 \pm 30.8 \mu \mathrm{m})$, 

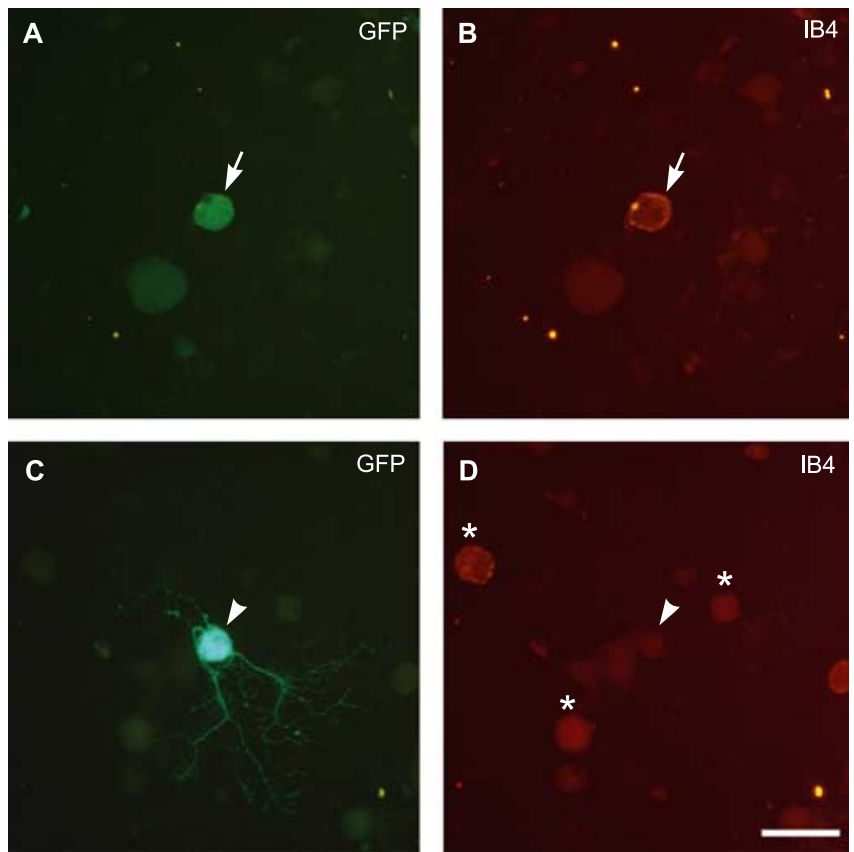

Figure 8. Forced expression of $\alpha 7$-integrin and GAP 43 fails to promote neurite outgrowth from IB4-labeled neurons. In cultures of DRG cells electroporated with CDNAs encoding $\alpha 7$ integrin, GAP 43 (together with GFP as a marker), GFP-positive neurons labeled by IB4 (arrows in $A, B$ ) did not usually show neurite outgrowth. In contrast, GFP-positive neurons not labeled by IB4 (arrowheads in $\boldsymbol{C}, \boldsymbol{D}$ ) often showed extensive neurite outgrowth, although neurite lengths did not appear greater in transfected neurons than in GAP 43-positive neurons in normal DRG cultures and were therefore not quantified. Some GFP-negative IB4-labeled neurons $\left({ }^{*}\right)$ without neurites are also visible in $\boldsymbol{D}$. Scale bar, $50 \mu \mathrm{m}$.

neonatal DRG cells were used in subsequent transfection studies. In three separate experiments, after electroporation of the plasmids encoding GAP 43, $\alpha 7$-integrin, and enhanced GFP, a mean of $8 \pm 1.2 \mathrm{GFP}$-positive/IB4-labeled neurons per well were visible (Fig. 8), but, of these, only $5.1 \pm 1.4 \%$ extended neurites and their mean length $(85.1 \pm 11.1 \mu \mathrm{m})$ was similar to values obtained from control (nonelectroporated) cultures. These results indicate that forced expression of GAP 43 together with $\alpha 7$-integrin fails to enhance neurite outgrowth from IB4-labeled DRG neurons.

\section{Neurite outgrowth in media conditioned by cultured peripheral nerve segments}

Although IB4-labeled neurons showed less spontaneous neurite outgrowth on laminin than other DRG neurons, they extend neurites in response to GDNF whose expression is increased in lesioned nerves (Trupp et al., 1995; Naveilhan et al., 1997; Bar et al., 1998; Hoke et al., 2000, 2002). We therefore investigated whether diffusible factors present in media conditioned by segments of normal or lesioned sciatic nerves could promote axonal growth of IB4-labeled neurons. We used PN-DRGs cultured in collagen gels (Tonge et al., 1998) in which quantification of axonal lengths is relatively easy because axons generally extend from the cut end of the peripheral nerves into the gels without branching, in contrast to the extensive branching observed in cultures of dissociated DRG neurons.

In initial experiments using an antibody to PGP 9.5 as a panneuronal marker, PN-DRGs cultured in medium conditioned by lesioned nerve segments (LNCM) showed a marked increase in the apparent numbers of outgrowing axons compared with control preparations (Fig. 9), and their mean length was more than doubled ( $p<0.001$ ) (Table 3). Interestingly, preparations cul-
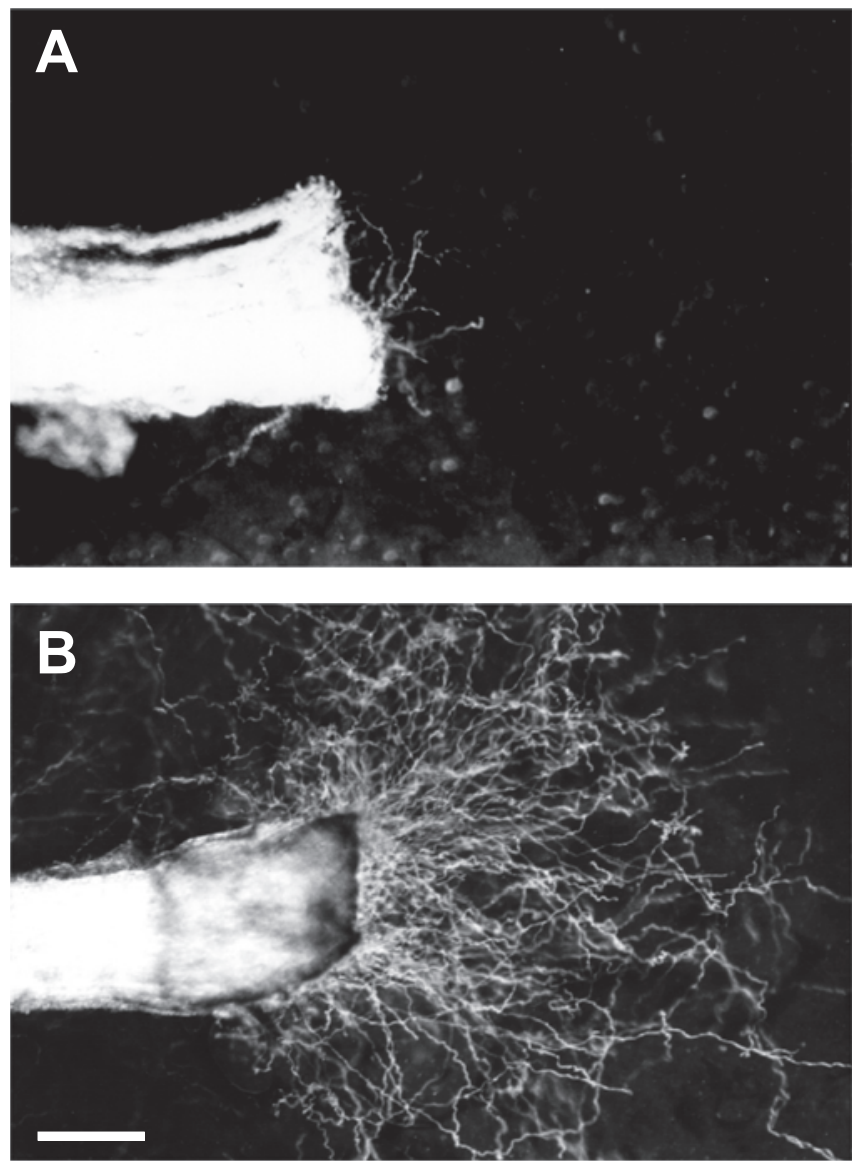

Figure 9. Conditioned medium enhances axonal outgrowth from PN-DRGs. PN-DRGs after culture in collagen gels for $3 \mathrm{~d}$, labeled with an antibody to PGP 9.5 (visualized with HRPconjugated avidin) taken using dark-ground illumination to make it easier to see fine axons at low magnification. In a control preparation $(\boldsymbol{A})$ cultured in RPMI medium, only a few axons have grown out of the cut end of the peripheral nerve, whereas extensive axonal outgrowth has occurred from a preparation cultured in medium conditioned by lesioned sciatic nerve segments (B). Scale bar, $200 \mu \mathrm{m}$.

Table 3. Media conditioned by nerve explants stimulates axonal growth

\begin{tabular}{lllll}
\hline Controls & LNCM & LNCM $+\alpha$-NGF & NNCM & NNCM $+\alpha$-NGF \\
\hline $252 \pm 8$ & $622 \pm 19$ & $315 \pm 19$ & $528 \pm 15$ & $310 \pm 21$ \\
$n=270(23)$ & $n=190(15)$ & $n=102(8)$ & $n=178(16)$ & $n=78(7)$ \\
\hline
\end{tabular}

Mean \pm SEM lengths (in micromolar) of axons in collagen gels after culture for $3 \mathrm{~d}$ in normal RPMI medium (controls), LNCM, or NNCM, with or without $\alpha$-NGF (mAb 27/21). The number of preparations examined is given in parentheses; $n=$ number of axons measured.

tured in medium conditioned by normal nerve segments also showed significantly $(p<0.001)$ increased axonal outgrowth length, but the mean lengths of the axons was slightly less than in LNCM (Table 3). In contrast, mean axonal lengths of PN-DRGs cultured in CM that had been mixed with mAb 21/27 before addition to the cultures were not significantly different from controls (Table 3 ). Because mAb 21/27 selectively blocks activity of NGF but not BDNF or NT-3 (Nanduri et al., 1994), it appears that most of the axonal growth-stimulating activity in both types of CM is attributable to NGF rather than other neurotrophins or GDNF. However, although recombinant GDNF stimulates axonal outgrowth from adult PN-DRGs in collagen gels, axons labeled by IB4 in such cultures were much shorter than those of other classes (Leclere et al., 1998). It is therefore possible that effects of GDNF present in the conditioned media samples might not be detected by sole measurement of axonal lengths. To deter- 
Table 4. GDNF stimulates outgrowth of IB4-positive axons from PN-DRG preparations

\begin{tabular}{ll}
\hline Condition & Mean number of IB4-labeled axons \\
\hline Controls & $5.8 \pm 0.8(n=18)$ \\
$50 \mathrm{ng} / \mathrm{ml}$ GDNF & $16.2 \pm 1.7(n=12)^{*}$ \\
$10 \mathrm{ng} / \mathrm{ml} \mathrm{GDNF}$ & $20 \pm 3.1(n=11)^{*}$ \\
$2 \mathrm{ng} / \mathrm{ml}$ GDNF & $12.3 \pm 3.1(n=9)^{* *}$ \\
$100 \mathrm{pg} / \mathrm{ml}$ GDNF & $4.2 \pm 0.4(n=8), \mathrm{NS}$ \\
$10 \mathrm{pg} / \mathrm{ml}$ GDNF & $4.0 \pm 0.6(n=12)$, NS \\
Mouse lesioned nerve CM & $5.1 \pm 1.0(n=16)$, NS \\
Rat lesioned nerve CM & $5.7 \pm 1.4(n=12)$, NS
\end{tabular}

Mean + SEM numbers of outgrowing IB4-labeled axons per PN-DRG preparation after 3 din culture in lesioned nerve $\mathrm{CM}$ (mouse or rat) or different concentrations of recombinant human GDNF. $n=$ number of PN-DRGs. ${ }^{*} p<$ $0.001 ; * * 0.05$

Table 5. Concentrations of NGF and GDNF in conditioned media

\begin{tabular}{lll}
\hline & NGF & GDNF \\
\hline Lesioned nerve CM (mouse) & $154 \pm 26(n=5)$ & $7 \pm 5(n=3)$ \\
Normal nerve CM (mouse) & $107 \pm 10(n=3)$ & $10(n=2)$ \\
Lesioned nerve CM (rat) & ND & $12(n=1)$ \\
\hline
\end{tabular}

Mean \pm SEM concentrations of NGF and GDNF (picograms per milliliter) in media conditioned by lesioned and normal nerve segments. $n=$ number of experiments. ND, Not determined.

mine directly whether nerve segments released physiologically detectable GDNF-like activity, PN-DRGs were incubated in CM or RPMI medium containing concentrations of GDNF varying between $10 \mathrm{pg} / \mathrm{ml}$ and $50 \mathrm{ng} / \mathrm{ml}$ for $3 \mathrm{~d}$ and then labeled using IB4 and Cy3- or TRITC-conjugated avidin. As in our previous study (Leclere et al., 1998), we found that $50 \mathrm{ng} / \mathrm{ml} \mathrm{GDNF}$ increased the numbers of outgrowing IB4-labeled axons and also observed significant increases at levels as low as $2 \mathrm{ng} / \mathrm{ml}$ but not at 100 or 10 $\mathrm{pg} / \mathrm{ml}$ (Table 4).

However, in preparations cultured in LNCM, although overall axonal outgrowth was clearly increased (Fig. 9), there was no increase in outgrowth of IB4-labeled axons (Table 4). These results suggest that GDNF levels in CM may be too low to stimulate outgrowth of IB4-labeled axons. To investigate this possibility, concentrations of NGF and GDNF in CM were determined by ELISA. The results (Table 5) show that both NGF and GDNF were detected in media conditioned by normal and lesioned nerve segments, but that the concentrations of GDNF are approximately an order of magnitude lower than those of NGF and are therefore too low to stimulate outgrowth of IB4-labeled axons.

The relatively poor neurite outgrowth from IB4-labeled neurons together with the low levels of GDNF released by lesioned peripheral nerves raise the possibility that axonal regeneration of this neuronal class might be impaired after peripheral nerve lesions in vivo. To investigate this possibility, we initially labeled frozen longitudinal sections of normal and previously crushed segments of sciatic nerve using IB4. However, although IB4labeled axons were visible in sections of normal nerve, in lesioned nerve, sections it was difficult to differentiate between the processes of the large numbers of IB4-labeled activated macrophages (Maddox et al., 1982) and regenerating IB4-labeled axons (data not shown). We therefore used an alternative method to determine whether IB4-labeled axons could regenerate after peripheral nerve crush. The three most caudal intercostal nerves were crushed unilaterally close to the vertebral column in six mice, which were then allowed to recover. After 2-3 weeks, the conditioned DRGs with $\sim 10 \mathrm{~mm}$ of the intercostal nerves (including the crush site), together with the unoperated contralateral PNDRGs, were carefully removed and cultured in collagen gels with RPMI medium containing NGF and GDNF (both at $50 \mathrm{ng} / \mathrm{ml}$ ).
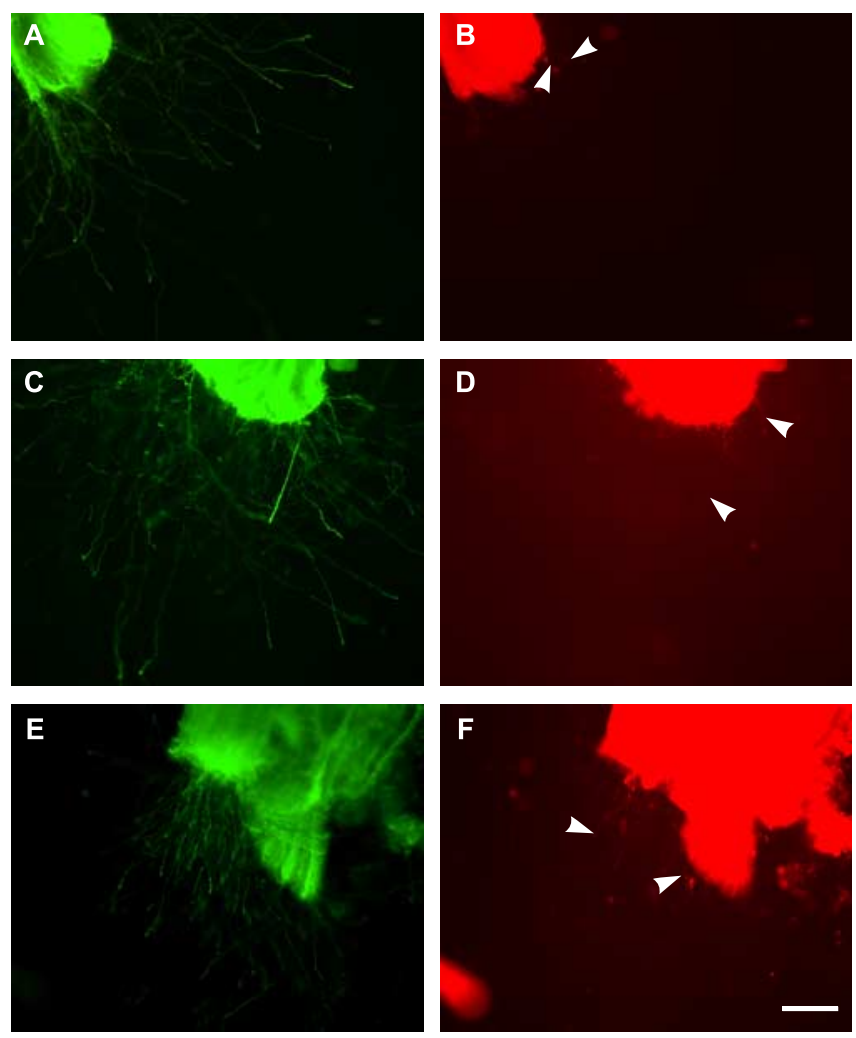

Figure 10. Regeneration of IB4-labeled and GAP 43-positive axons after peripheral nerve crush. PN-DRGs in collagen gels after $3 \mathrm{~d}$ in culture with NGF and GDNF, labeled green using antibody to GAP 43 immunoreactivity and red to visualize IB4 binding. In contralateral control preparations $(\boldsymbol{A}, \boldsymbol{B})$ and preparations conditioned by intercostal nerve crush 3 weeks earlier but trimmed proximal to the original crush site $(\boldsymbol{C}, \boldsymbol{D})$, numerous GAP 43-positive axons extend from cut ends of the peripheral nerve $(\boldsymbol{A}, \boldsymbol{C})$. Small numbers of IB4-labeled axons (arrowheads) are also visible $(\boldsymbol{B}, \boldsymbol{D})$, but these are usually also GAP 43 positive and are invariably much shorter than the GAP 43-positive/IB4-negative axons, indicating impaired growth in collagen gels. In cultured conditioned preparations that include the original crush site and $\sim 5 \mathrm{~mm}$ of distal nerve $(\boldsymbol{E}, \boldsymbol{F})$, GAP 43-positive axons and IB4-labeled (arrowheads) axons extend from the cut nerve ends into the gels, indicating that both classes of axons have regenerated through the initial crush site, although IB4-labeled axons were invariably shorter than IB4-negative ones. Scale bar, $100 \mu \mathrm{m}$.

In the contralateral control preparations, vigorous outgrowth of GAP 43-positive axons from the cut end of the intercostal nerves was observed as expected (Fig. 10A) but relatively few short IB4labeled axons (Fig. $10 \mathrm{~B}$ ) as observed in a previous study (Leclere et al., 1998). In three conditioned preparations in which the intercostals nerve was cut proximal to the initial crush site, before culture in the collagen gels, marked increase in outgrowth of GAP 43-positive axons (Fig. 10C) together with a modest increase in outgrowth of short IB4-labeled axons was observed (Fig. $10 \mathrm{D}$ ). In the nine conditioned preparations in which the intercostal nerve segments included the initial crush site, GAP 43-positive axons had extended into the collagen gels from the cut nerve ends (Fig. $10 E$ ), indicating that they had successfully regenerated after the initial nerve crush in vivo. In most preparations, we also observed small numbers of short IB4-labeled axons extending from the cut ends of the intercostal nerves (Fig. $10 \mathrm{~F}$ ), indicating that they had also regenerated. Interestingly, these IB4-labeled axons extending into the collagen were generally also GAP 43 positive, suggesting that the capacity for axon regeneration of this small subpopulation ( $<1 \%$ of dually labeled neurons in dissociated cultures) may be better than that of the majority IB4-labeled population. It is likely 
that the subpopulation of IB4-labeled neurons expressing GAP 43 also express other proteins required for axonal regeneration.

\section{Discussion}

It is well established that dissociated DRG neurons of adult rats and mice can extend neurites in the presence of laminin in the absence of added neurotrophic factors and that this outgrowth is greatly enhanced by previous axotomy in vivo (Hu-Tsai et al., 1994; Edström et al., 1996; Smith and Pate Skene, 1997; Lankford et al., 1998; Liu and Snider, 2001; Ekström et al., 2003). In the present study, we found that neurons labeled by RT97 showed profuse spontaneous neurite outgrowth on laminin, but that neurite outgrowth from the IB4-labeled neurons was markedly inferior. In cultures of dissociated cells from conditioned DRGs, neurite outgrowth from both classes was increased, but the proportions of IB4-labeled neurons extending neurites and also their lengths remained inferior to the RT97-positive neurons.

The reasons for the impaired neurite outgrowth of the IB4labeled neurons on laminin are uncertain but might be attributable to lack of expression of $\alpha 7$-integrin, recently reported by Gardiner et al. (2005), and/or GAP 43, as found in the present study and also noted by Verge et al. (1990). To investigate these possibilities, we infected dissociated DRG neurons with an HSV-1 vector encoding the $\alpha 7 \mathrm{BX} 2$-integrin isoform normally expressed in DRGs (Ekström et al., 2003). However, forced expression of this integrin subunit failed to promote neurite outgrowth from either IB4-labeled or IB4-negative DRG neurons. The failure of $\alpha 7$-integrin to promote neurite outgrowth in DRG neurons seems unlikely to be attributable to lack of expression of its $\beta 1$ subunit partner because this appears to be expressed by all DRG neurons (Gardiner et al., 2005), although an imbalance in levels of expression of subunits, possibly causing dominantnegative actions, cannot be excluded. We also electroporated DRG cells with plasmids encoding $\alpha 7$-integrin and GAP 43, but coexpression of both proteins also failed to enhance neurite outgrowth from IB4-labeled neurons. One explanation for the findings is that other proteins or signaling molecules (in addition to $\alpha 7$-integrin and GAP 43) are required for neurite outgrowth. Consistent with this hypothesis, expression of $\beta$ III-tubulin, usually upregulated in regenerating primary sensory axons (Moskowitz and Oblinger, 1995), appeared lower in IB4-labeled neurons than in IB4-negative neurons. IB4-labeled neurons may well fail to synthesize other proteins involved in axonal regeneration. For example, axonal extension into three-dimensional extracellular matrices requires activity of metalloproteinases (for review, see McFarlane, 2003). It is therefore noteworthy that, although IB4-labeled neurons show extensive neurite outgrowth on laminin in response to GDNF (Gavazzi et al., 1999; Gardiner et al., 2005), their ability to extend axons into collagen gels is markedly inferior to that of other neuronal classes (Leclere et al., 1998 and the present study). These results suggest that axonal regeneration of IB4-labeled neurons is intrinsically different from that of other classes of DRG neurons, although after sciatic nerve section they do express SPRR1A, which is also associated with axonal regeneration (Bonilla et al., 2002).

Although spontaneous neurite outgrowth of IB4-labeled neurons on laminin is poor, they extend neurites readily in response to GDNF whose expression is increased in lesioned peripheral nerves (Trupp et al., 1995; Naveilhan et al., 1997; Bar et al., 1998; Hoke et al., 2000, 2002). Because degenerating nerves of rats, mice, chickens, and frogs are known to release factors that stimulate neurite outgrowth from sympathetic ganglia and DRGs (Richardson and Ebendal, 1982; Windebank and Poduslo, 1986;
Ferguson et al., 1989; Kuffler and Megwinoff, 1994; Tonge et al., 1996), we tested effects of media conditioned by segments of lesioned and normal nerves on explanted PN-DRG preparations to see whether stimulation of axonal outgrowth of IB4-labeled axons in collagen gels would occur. However, although we observed profuse outgrowth of PGP 9.5-positive axons in the collagen gels in media conditioned by peripheral nerve segments (which was primarily abolished by a neutralizing antibody to NGF), there was no stimulation of outgrowth of IB4-labeled axons. These results suggest that, whereas levels of NGF in the conditioned media are sufficient to promote neurite outgrowth, as observed in other studies (Richardson and Ebendal, 1982; Ferguson et al., 1989; Kuffler and Megwinoff, 1994), levels of GDNF and other neurotrophic factors released from the cultured nerve segments may be insufficient to promote axonal growth. These findings were unexpected given that increased expression of GDNF (at mRNA level) in lesioned nerves has been observed in several studies (Trupp et al., 1995; Naveilhan et al., 1997; Bar et al., 1998; Hoke et al., 2000). We therefore measured concentrations of NGF and GDNF in CM by ELISA. The levels of NGF in media conditioned by normal mouse sciatic nerves $(\sim 100 \mathrm{pg} / \mathrm{ml})$ were similar to those measured in media conditioned by normal rat sciatic nerves by Ferguson et al. (1989) and may be attributable to synthesis by Schwann cells deprived of axon contact (Meyer et al., 1992). In media conditioned by lesioned mouse sciatic nerves, NGF were higher $(\sim 150 \mathrm{pg} / \mathrm{ml})$, probably resulting from increased synthesis by fibroblasts in response to interleukin-1 released from macrophages accumulating in peripheral nerves during Wallerian degeneration (Heumann et al., 1987). In contrast, levels of GDNF in media conditioned by rat and mouse sciatic nerves were approximately an order of magnitude less than NGF levels and therefore too low to stimulate axonal growth. Levels of GDNF measured in normal and lesioned rat sciatic nerves vary between 0.17 and $0.53 \mathrm{ng}$ per $1 \mathrm{mg} / \mathrm{ml}$ total protein (Hoke et al., 2002), but the proportion of GDNF present extracellularly and therefore available to influence axonal growth is not known.

The relatively low levels of GDNF produced after nerve lesions compared with NGF, together with the intrinsically poor regenerative capacity of the IB4-labeled neuron population, may have important physiological consequences. IB4-labeled neurons are nociceptive (Hunt and Mantyh, 2001) and project mainly to the epidermis (Lu et al., 2001). During embryonic development, this neuron population appears to depend on NGF for survival initially but downregulates trkA during early postnatal life and thereafter becomes dependent on GDNF (Molliver and Snider, 1997; Molliver et al., 1997), but the reasons for these changes in trophic dependence and their physiological significance are uncertain. In adult animals, it is well established that projections of IB4-labeled neurons in the dorsal horn regress after PNS lesions (White et al., 1990; Bennett et al., 1998; Bailey and Ribeiro-daSilva, 2006), although projections of CGRP-positive neurons appear less affected. One consequence of the regression of the IB4labeled axonal projection is that it might allow sprouting of other classes of axons into the denervated territory, which could contribute to hyperalgesia associated with nerve lesions (Doubell et al., 1997), although this hypothesis has been challenged (Bao et al., 2002; Hughes et al., 2003; Shehab et al., 2004). However, in animal models of neuropathic pain, the associated hyperalgesia may be reduced by intrathecal infusions of GDNF (Boucher and McMahon, 2001), and such infusions also prevent the regression of the IB4 labeling in the dorsal horns after PN injury (Bennett et al., 1998). Because peripheral nerve lesions result in upregulation 
of GDNF, it might be expected that this should prevent regression of the IB4-labeled axonal projection to the dorsal horns of the spinal cord and also development of hyperalgesia. However, the relatively low levels of GDNF in media conditioned by lesioned peripheral nerves observed in the present study suggest that its endogenous production may be inadequate to prevent phenotypic changes associated with axotomy in DRG neurons (for review, see Boucher and McMahon, 2001) and provide a rational basis for GDNF infusions in the treatment of nerve injuries.

The failure of IB4-labeled axons to grow extensively in threedimensional collagen gels in response to GDNF may also be physiologically important. GDNF is present in the skin of adult animals (Botchkareva et al., 2000) at low levels ( $\sim 15 \mathrm{pg} / \mathrm{mg}$ ), but effects of inflammation or injury on its expression do not appear to have been investigated and it is not known whether the levels of GDNF in lesioned/inflamed skin could stimulate axonal growth. NGF is also present in skin in which its synthesis is increased after injury (Ueda et al., 2002) and may cause collateral axonal sprouting (Diamond et al., 1992) as well as contributing to nociceptor sensitization (for review, see Shu and Mendell, 1999). In neonatal animals, skin lesions cause more vigorous axonal sprouting than in adult animals, leading to persistent hyperinnervation and hyperalgesia (Reynolds and Fitzgerald, 1995). In part, this may be attributable to the higher levels of NGF synthesized in lesioned skin of neonatal animals (Constantinou et al., 1994). In adult animals, the loss of responsiveness to NGF by the IB4-labeled neurons together with their poor ability to penetrate threedimensional matrices may also limit the degree of axonal sprouting in response to neurotrophic factors released in lesioned tissues and prevent or reduce the hyperalgesia that might otherwise occur as a result of such sprouting.

\section{References}

Averill S, McMahon SB, Clary DO, Reichardt LF, Priestley JV (1995) Immunocytochemical localization of trkA receptors in chemically identified subgroups of adult rat sensory neurons. Eur J Neurosci 7:1484-1494.

Bailey AL, Ribeiro-da-Silva A (2006) Transient loss of terminals from nonpeptidergic nociceptive fibers in the substantia gelatinosa of spinal cord following chronic constriction injury of the sciatic nerve. Neuroscience 138:675-690.

Baloh RH, Enomoto H, Johnson Jr EM, Milbrandt J (2000) The GDNF family ligands and receptors: implications for neural development. Curr Opin Neurobiol 10:103-110.

Bao L, Wang HF, Cai HJ, Tong YG, Jin SX, Lu YJ, Grant G, Hokfelt T, Zhang $X$ (2002) Peripheral axotomy induces only very limited sprouting of coarse myelinated afferents into inner lamina II of rat spinal cord. Eur J Neurosci 16:175-185.

Bar KJ, Saldanha GJ, Kennedy AJ, Facer P, Birch R, Carlstedt T, Anand P (1998) GDNF and its receptor component Ret in injured human nerves and dorsal root ganglia. NeuroReport 9:43-47.

Bates CA, Meyer RL (1997) The neurite-promoting effect of laminin is mediated by different mechanisms in embryonic and adult regenerating mouse optic axons in vitro. Dev Biol 181:91-101.

Baudet C, Mikaels A, Westphal H, Johansen J, Johansen TE, Ernfors P (2000) Positive and negative interactions of GDNF, NTN and ART in developing sensory neuron subpopulations, and their collaboration with neurotrophins. Development 127:4335-4344.

Bennett DL, Michael GJ, Ramachandran N, Munson JB, Averill S, Yan Q, McMahon SB, Priestley JV (1998) A distinct subgroup of small DRG cells express GDNF receptor components and GDNF is protective for these neurons after nerve injury. J Neurosci 18:3059-3072.

Bennett DL, Boucher TJ, Armanini MP, Poulsen KT, Michael GJ, Priestley JV, Phillips HS, McMahon SB, Shelton DL (2000) The glial cell line-derived neurotrophic factor family receptor components are differentially regulated within sensory neurons after nerve injury. J Neurosci 20:427-437.

Benowitz LI, Routenberg A (1997) GAP-43: an intrinsic determinant of neuronal development and plasticity. Trends Neurosci 20:84-91.

Bomze HM, Bulsara KR, Iskandar BJ, Caroni P, Skene JH (2001) Spinal axon regeneration evoked by replacing two growth cone proteins in adult neurons. Nat Neurosci 4:38-43.

Bonilla IE, Tanabe K, Strittmatter SM (2002) Small proline-rich repeat protein $1 \mathrm{~A}$ is expressed by axotomized neurons and promotes axonal outgrowth. J Neurosci 22:1303-1315.

Botchkareva NV, Botchkarev VA, Welker P, Airaksinen M, Roth W, Suvanto P, Muller-Rover S, Hadshiew IM, Peters C, Paus R (2000) New roles for glial cell line-derived neurotrophic factor and neurturin: involvement in hair cycle control. Am J Pathol 156:1041-1053.

Boucher TJ, McMahon SB (2001) Neurotrophic factors and neuropathic pain. Curr Opin Pharmacol 1:66-72.

Constantinou J, Reynolds ML, Woolf CJ, Safieh-Garabedian B, Fitzgerald M (1994) Nerve growth factor levels in developing rat skin: upregulation following skin wounding. NeuroReport 5:2281-2284.

Dethleffsen K, Morl K, Meyer M (2002) Control of local NGF mRNA synthesis by preformed factors rapidly released from peripheral nerves. Mol Cell Neurosci 20:503-514.

Diamond J, Holmes M, Coughlin M (1992) Endogenous NGF and nerve impulses regulate the collateral sprouting of sensory axons in the skin of the adult rat. J Neurosci 12:1454-1466.

Doubell TP, Mannion RJ, Woolf CJ (1997) Intact sciatic myelinated primary afferent terminals collaterally sprout in the adult rat dorsal horn following section of a neighbouring peripheral nerve. J Comp Neurol 380:95-104.

Eble JA, Bruckner P, Mayer U (2003) Vipera lebetina venom contains two disintegrins inhibiting laminin-binding beta 1 integrins. J Biol Chem 278:26488-26496.

Edström A, Ekström PAR, Tonge D (1996) Axonal outgrowth and neuronal apoptosis in cultured adult mouse DRG preparations: effects of neurotrophins, of inhibition of neurotrophin actions, and of prior axotomy. Neuroscience 75:1165-1174.

Ekström PA, Mayer U, Panjwani A, Pountney D, Pizzey J, Tonge DA (2003) Involvement of alpha7betal integrin in the conditioning-lesion effect on sensory axon regeneration. Mol Cell Neurosci 22:383-395.

Ferguson IA, Williams R, Rush RA (1989) Chicken NGF and non-NGF trophic factor synthesis and release by sciatic nerves in vitro. J Neurosci Res 22:408-417.

Fine EG, Decosterd I, Papaloizos M, Zurn AD, Aebischer P (2002) GDNF and NGF released by synthetic guidance channels support sciatic nerve regeneration across a long gap. Eur J Neurosci 15:589-601.

Flecknell PA, Mitchell M (1984) Midazolam and fentanyl-fluanisone: assessment of anaesthetic effects in laboratory rodents and rabbits. Lab Anim 18:143-146.

Funakoshi H, Frisen J, Barbany G, Timmusk T, Zachrisson O, Verge VMK, Persson H (1993) Differential expression of mRNAs for neurotrophins and their receptors after axotomy of the sciatic nerve. J Cell Biol 123:455-465.

Gardiner NJ, Fernyhough P, Tomlinson DR, Mayer U, von der Mark H, Streuli $\mathrm{CH}$ (2005) Alpha7 integrin mediates neurite outgrowth of distinct populations of adult sensory neurons. Mol Cell Neurosci 28:229-240.

Gavazzi I, Kumar KD, McMahon SB, Cohen J (1999) Growth responses of different subpopulations of adult sensory neurons to neurotrophic factors in vitro. Eur J Neurosci 11:3405-3414.

Heumann R, Korsching S, Bandtlow C, Thoenen H (1987) Changes of nerve growth factor synthesis in non-neuronal cells in response to sciatic nerve transection. J Cell Biol 104:1623-1631.

Hoke A, Cheng C, Zochodne DW (2000) Expression of glial cell linederived neurotrophic factor family of growth factors in peripheral nerve injury in rats. NeuroReport 11:1651-1654.

Hoke A, Gordon T, Zochodne DW, Sulaiman OA (2002) A decline in glial cell-line-derived neurotrophic factor expression is associated with impaired regeneration after long-term Schwann cell denervation. Exp Neurol 173:77-85.

Hu-Tsai M, Winter J, Emson PC, Woolf CJ (1994) Neurite outgrowth and GAP 43 expression in cultured adult rat dorsal root ganglion neurons: effects of NGF or prior peripheral axotomy. J Neurosci Res 39:634-645.

Huang EJ, Reichardt LF (2001) Neurotrophins: roles in neuronal development and function. Annu Rev Neurosci 24:677-736.

Hughes DI, Scott DT, Todd AJ, Riddell JS (2003) Lack of evidence for sprouting of Abeta afferents into the superficial laminas of the spinal cord dorsal horn after nerve section. J Neurosci 23:9491-9499. 
Hunt SP, Mantyh PW (2001) The molecular dynamics of pain control. Nat Rev Neurosci 2:83-91.

Ide C (1996) Peripheral nerve regeneration. Neurosci Res 25:101-121.

Kimpinski K, Campenot RB, Mearow K (1997) Effects of the neurotrophins nerve growth factor, neurotrophin-3, and brain-derived neurotrophic factor (BDNF) on neurite growth from adult sensory neurons in compartmented cultures. J Neurobiol 33:395-410.

Kuffler DP, Megwinoff O (1994) Neurotrophic influence of denervated sciatic nerve on adult dorsal root ganglion neurons. J Neurobiol 25:1267-1282.

Lankford KL, Waxman SG, Kocsis JD (1998) Mechanisms of enhancement of neurite regeneration in vitro following a conditioning sciatic nerve lesion. J Comp Neurol 391:11-29.

Leclere P, Ekström P, Edstrom A, Priestley J, Averill S, Tonge DA (1998) Effects of glial cell line-derived neurotrophic factor on axonal growth and apoptosis in adult mammalian sensory neurons in vitro. Neuroscience 82:545-558.

Leclere PG, Panjwani A, Docherty R, Berry M, Pizzey J, Tonge DA (2005) Effective gene delivery to adult neurons by a modified form of electroporation. J Neurosci Methods 142:137-143.

Lee YJ, Zachrisson O, Tonge DA, McNaughton PA (2002) Upregulation of bradykinin B2 receptor expression by neurotrophic factors and nerve injury in mouse sensory neurons. Mol Cell Neurosci 19:186-200.

Lilley CE, Groutsi F, Han Z, Palmer JA, Anderson PN, Latchman DS, Coffin RS (2001) Multiple immediate-early gene-deficient herpes simplex virus vectors allowing efficient gene delivery to neurons in culture and widespread gene delivery to the central nervous system in vivo. J Virol 75:4343-4356.

Lindsay RM (1988) Nerve growth factors (NGF, BDNF) enhance axonal regeneration but are not required for survival of adult sensory neurons. J Neurosci 8:2394-2408.

Liu RY, Snider WD (2001) Different signaling pathways mediate regenerative versus developmental sensory axon growth. J Neurosci 21:RC164(1-5).

Lu J, Zhou XF, Rush RA (2001) Small primary sensory neurons innervating epidermis and viscera display differential phenotype in the adult rat. Neurosci Res 41:355-363.

Luckenbill-Edds L (1997) Laminin and the mechanism of neuronal outgrowth. Brain Res Brain Res Rev 23:1-27.

Maddox DE, Shibata S, Goldstein IJ (1982) Stimulated macrophages express a new glycoprotein receptor reactive with Griffonia simplicifolia I-B4 isolectin. Proc Natl Acad Sci USA 79:166-170.

Malgrange B, Delree P, Rigo JM, Baron H, Moonen G (1994) Image analysis of neuritic regeneration by adult rat dorsal root ganglion neurons in culture: quantitation of the neurotoxicity of anticancer agents and of its prevention by nerve growth factor or basic fibroblast growth factor but not by brain-derived neurotrophic factor or neurotrophin-3. J Neurosci Methods 53:111-122.

McFarlane S (2003) Metalloproteases: carving out a role in axon guidance. Neuron 37:559-562.

McMahon SB, Armanini MP, Ling LH, Phillips HS (1994) Expression and coexpression of Trk receptors in subpopulations of adult primary sensory neurons projecting to identified peripheral targets. Neuron 12:1161-1171.

Meyer M, Matsuoka I, Wetmore C, Olsen L, Thoenen H (1992) Enhanced synthesis of brain-derived neurotrophic factor in the lesioned peripheral nerve: different mechanisms are responsible for the regulation of BDNF and NGF mRNA. J Cell Biol 119:45-54.

Mohiuddin L, Fernandez K, Tomlinson DR, Fernyhough P (1995) Nerve growth factor and neurotrophin-3 enhance neurite outgrowth and upregulate the levels of messenger RNA for growth-associated protein GAP-43 and T $\alpha 1 \alpha$-tubulin in cultured adult rat sensory neurons. Neurosci Lett 185:20-23.

Molliver DC, Snider WD (1997) Nerve growth factor receptor TrkA is down-regulated during postnatal development by a subset of dorsal root ganglion neurons. J Comp Neurol 19:428-438.

Molliver DC, Wright DE, Leitner ML, Parsadanian AS, Doster K, Wen D, Yan Q, Snider WD (1997) IB4-binding DRG neurons switch from NGF to GDNF dependence in early postnatal life. Neuron 19:849-861.

Moskowitz PF, Oblinger MM (1995) Sensory neurons selectively upregulate synthesis and transport of the beta III-tubulin protein during axonal regeneration. J Neurosci 15:1545-1555.
Nanduri J, Vroegop SM, Buxser SE, Neet KE (1994) Immunological determinants of nerve growth factor involved in p140trk (Trk) receptor binding. J Neurosci Res 37:433-444.

Naveilhan P, ElShamy WM, Ernfors P (1997) Differential regulation of mRNAs for GDNF and its receptors Ret and GDNFR alpha after sciatic nerve lesion in the mouse. Eur J Neurosci 9:1450-1460.

Ramer MS, Priestley JV, McMahon SB (2000) Functional regeneration of sensory axons into the adult spinal cord. Nature 403:312-316.

Reynolds ML, Fitzgerald M (1995) Long-term sensory hyperinnervation following neonatal skin wounds. J Comp Neurol 358:487-498.

Richardson PM, Ebendal T (1982) Nerve growth activities in rat peripheral nerve. Brain Res 246:57-64.

Shehab SA, Spike RC, Todd AJ (2004) Do central terminals of intact myelinated primary afferents sprout into the superficial dorsal horn of rat spinal cord after injury to a neighboring peripheral nerve? J Comp Neurol 474:427-437.

Shu XQ, Mendell LM (1999) Neurotrophins and hyperalgesia. Proc Natl Acad Sci USA 96:7693-7696.

Smith DS, Pate Skene JH (1997) A transcription-dependent switch controls competence of adult neurons for distinct modes of axonal growth. J Neurosci 17:646-658.

Thomas SK, Lilley CE, Latchman DS, Coffin RS (1999) Equine herpesvirus 1 gene 12 can substitute for vmw65 in the growth of herpes simplex virus (HSV) type 1, allowing the generation of optimized cell lines for the propagation of HSV vectors with multiple immediate-early gene defects. J Virol 73:7399-7409.

Tonge DA, Aaronson OS, Golding JP, Jaggers D (1996) Cellular migration and axonal outgrowth from adult mammalian peripheral nerves in vitro. J Neurobiol 29:151-164.

Tonge D, Edstrom S, Ekström P (1998) Use of explant cultures of peripheral nerves of adult vertebrates to study axonal regeneration in vitro. Prog Neurobiol 54:459-480.

Trupp M, Rydén M, Jörnvall H, Funakoshi H, Timmusk T, Arenas E, Ibanéz CF (1995) Peripheral expression and biological activities of GDNF, a new neurotrophic factor for avian and mammalian peripheral neurons. J Cell Biol 130:137-148.

Ueda M, Hirose M, Takei N, Ibuki T, Naruse Y, Amaya F, Ibata Y, Tanaka M (2002) Nerve growth factor induces systemic hyperalgesia after thoracic burn injury in the rat. Neurosci Lett 328:97-100.

Vellani V, Zachrisson O, McNaughton PA (2004) Functional bradykinin B1 receptors are expressed in nociceptive neurones and are upregulated by the neurotrophin GDNF. J Physiol (Lond) 560:391-401.

Verge VM, Tetzlaff W, Richardson PM, Bisby MA (1990) Correlation between GAP43 and nerve growth factor receptors in rat sensory neurons. J Neurosci 10:926-934.

Wallquist W, Zelano J, Plantman S, Kaufman SJ, Cullheim S, Hammarberg H (2004) Dorsal root ganglion neurons up-regulate the expression of laminin-associated integrins after peripheral but not central axotomy. J Comp Neurol 480:162-169.

Werner A, Willem M, Jones LL, Kreutzberg GW, Mayer U, Raivich G (2000) Impaired axonal regeneration in $\alpha 7$ integrin-deficient mice. J Neurosci 20:1822-1830.

White FA, Bennett-Clarke CA, Macdonald GJ, Enfiejian HL, Chiaia NL, Rhoades RW (1990) Neonatal infraorbital nerve transection in the rat: comparison of effects on substance $\mathrm{P}$ immunoreactive primary afferents and those recognized by the lectin Bandierea simplicifolia-I. J Comp Neurol 300:249-262.

Wiklund P, Ekström PA (2000) Axonal outgrowth from adult mouse nodose ganglia in vitro is stimulated by neurotrophin- 4 in a Trk receptor and mitogen-activated protein kinase-dependent way. J Neurobiol 45:142-151.

Wilson POG, Barber PC, Hamid QA, Power BF, Dhillon AP, Rhode J, Day INM, Thompson RJ, Polak JM (1988) Immunolocalization of protein gene product 9.5 using rabbit polyclonal and mouse monoclonal antibodies. Br J Exp Pathol 69:91-104.

Windebank AJ, Poduslo JF (1986) Neuronal growth factors produced by adult peripheral nerve after injury. Brain Res 385:197-200.

Zhang Y, Bo X, Schoepfer R, Holtmaat AJ, Verhaagen J, Emson PC, Lieberman AR, Anderson PN (2005) Growth-associated protein GAP-43 and L1 act synergistically to promote regenerative growth of Purkinje cell axons in vivo. Proc Natl Acad Sci USA 102:14883-14888. 